\title{
Report on Development of Concepts for the Advanced Casting System in Support of the Deployment of a Remotely Operable Research Scale Fuel Fabrication Facility for Metal Fuel
}

K. Marsden

March 2007

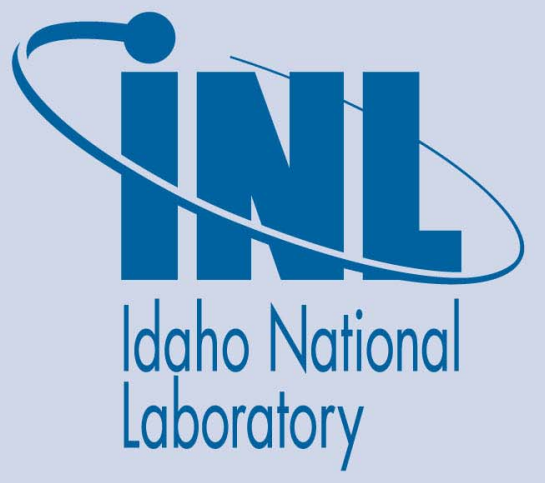

The INL is a U.S. Department of Energy National Laboratory operated by Battelle Energy Alliance 


\section{Report on Development of Concepts for the Advanced Casting System in Support of the Deployment of a Remotely Operable Research Scale Fuel Fabrication Facility for Metal Fuel}

K. Marsden

March 2007

Idaho National Laboratory

Idaho Falls, Idaho 83415

Prepared for the

U.S. Department of Energy

Office of Nuclear Energy

Under DOE Idaho Operations Office

Contract DE-AC07-05ID14517 


\section{Abstract}

Demonstration of recycle processes with low transuranic losses is key to the successful implementation of the Global Nuclear Energy Partnership strategy to manage spent fuel. It is probable that these recycle processes will include remote fuel fabrication. This report outlines the strategy to develop and implement a remote metal fuel casting process with minimal transuranic losses. The approach includes a bench-scale casting system to develop materials, methods, and perform tests with transuranics, and an engineering-scale casting system to demonstrate scalability and remote operability. These systems will be built as flexible test beds allowing exploration of multiple fuel casting approaches. The final component of the remote fuel fabrication demonstration culminates in the installation of an advanced casting system in a hot cell to provide integrated remote operation experience with low transuranic loss. Design efforts and technology planning have begun for the bench-scale casting system, and this will become operational in fiscal year 2008, assuming appropriate funding. Installation of the engineering-scale system will follow in late fiscal year 2008, and utilize materials and process knowledge gained in the bench-scale system. Assuming appropriate funding, the advanced casting system will be installed in a remote hot cell at the end of fiscal year 2009.

\subsection{Introduction}

Demonstration of low transuranic (TRU) loss recycle processes is key to the successful implementation of the Global Nuclear Energy Partnership (GNEP) strategy to manage spent fuel from global deployment of power reactors and to destroy transuranics in legacy spent nuclear fuel. As a part of the spent fuel recycle process, TRU loss issues exist during the fabrication of both metallic and oxide fuels that remain to be quantified and systematically addressed. Additionally, it is probable that remote fuel fabrication processes will be required for fuel fabrication. This report outlines the strategy for addressing both TRU retention and remote operation aspects of metallic fuel fabrication.

Issues critical to fabrication of transuranic-bearing fuels include losses of volatile constituents from the crucible during heating and casting, fuel holdup in crucibles and molds, fuel lost into dross from crucible and mold wash coatings, and the generation of contaminated wastes such as quartz mold pieces.

Remote implementation issues are ultimately addressed through the platform of the Research Scale Fuel Fabrication Facility (RSFFF) project. The RSFFF concept is a small-scale, remotelyoperable fuel fabrication laboratory designed as a demonstration of transuranic fuel fabrication technology prior to deployment of a larger-scale facility such as the Advanced Fuel Cycle Facility (AFCF). Implementation in the RSFFF demonstrates a scalable, remotely-operable metal fuel casting process with extremely small minor actinide losses. It is the intent of the Advanced Casting System work to integrate with RSFFF. This integration is described in more detail in a companion report on the design concepts and strategy for RSFFF [1].

Implementation of the RSFFF and Advanced Casting Furnace (ACS) builds upon previous fully remote fuel fabrication work completed as part of the EBR-II fuel cycle demonstration that 
began in the 1960's [2] and the Integral Fast Reactor Program in the 1980's and 1990's. During the earlier campaign, more than 30,000 fuel pins were remotely fabricated in the FCF (Fuel Conditioning Facility), the proposed location for RSFFF. Small scale research conducted as part of the Advanced Fuel Cycle Initiative (AFCI) Fuel Development Program has shown that americium loss issues associated with the fabrication of the americium-bearing experiment in the early 1990's [3] are understood and resolvable.

GNEP TRU fuel fabrication requirements will be met through the development of an Advanced Casting System (ACS) that is designed to meet GNEP program requirements for TRU loss and its installation into RSFFF. The ACS effort was initiated as a process and technology development effort to demonstrate minimal actinide fuel loss by rapid melting and casting under careful atmosphere control in reusable crucibles and molds. Development of the ACS includes:

- Design and construction of a bench-scale casting system (BCS) for use with minor actinide bearing fuel alloys to demonstrate minimal TRU loss

- Design and construction of an engineering-scale metal fuel casting system to demonstrate scale up

- Installation of a remotized engineering scale casting system (ECS) into RSFFF to constitute an advanced remotely-operable casting process which meets GNEP objectives. This system is called the ACS.

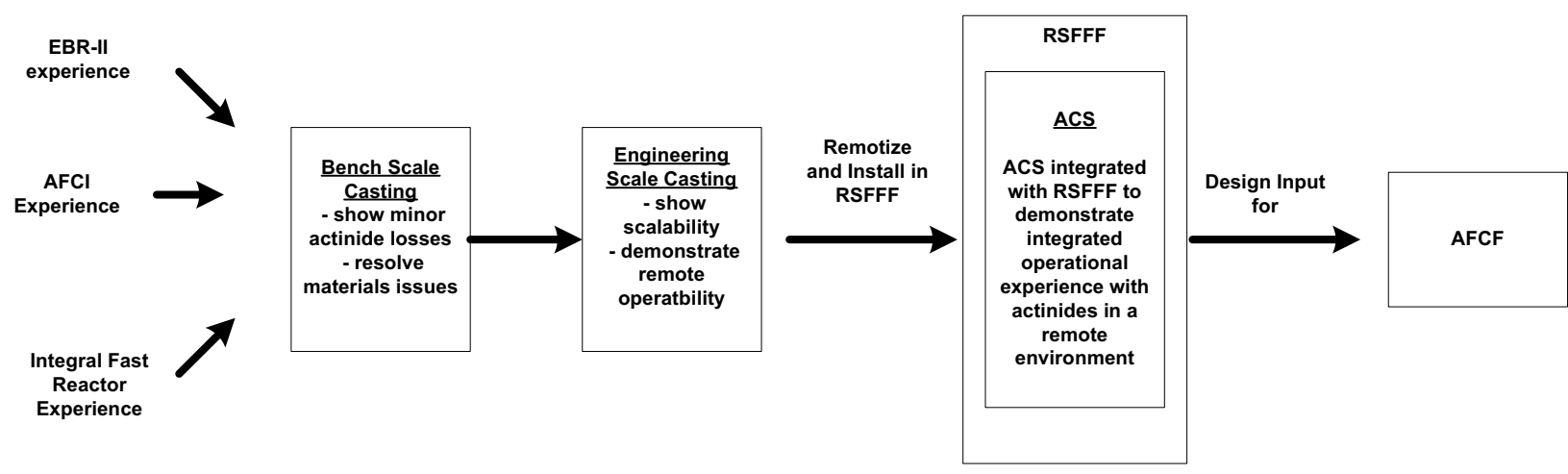

The two casting development systems are being designed with the flexibility to be configured to test a variety of casting techniques, crucible and mold materials, and injection pressure strategies. Technologies and processes developed will be consistent with eventual production-scale application in the remote operations environment.

In addition to addressing these global issues, an improvement of the current laboratory TRU fuel casting process offers significant widespread benefit to the fuel irradiation testing and characterization aspects of the advanced fuel cycle research and development (AFCRD) fuel development program. 
This report summarizes the objectives of the ACS, the status of the conceptual design, and the schedule for design, assembly and installation. This satisfies the deliverable and milestone objective of GNEP work package PIN07RDTF05 for this report.

\subsection{Approach, Objectives, and Timeline for the ACS}

\subsection{Approach to Advanced Casting Furnace Development}

Development of the ACS will proceed through the deployment of two flexible R\&D test beds designed to facilitate experimentation that leads to optimization of the ACS design. The first operational system will be the bench-scale caster, sized for 50-300 gram castings. The second operational system will be the engineering-scale system, sized for 1-6 kilogram castings. Both contain induction-heated crucibles and molds, as this technology is well demonstrated in remote environments, is easily scalable, and is easily automated. Both will also include the capability to be configured for the traditional pressure differential-driven counter-gravity fuel casting, and bottom-poured casting assisted by a pressure differential.

The bench-scale caster will be mobile, with a self contained control system and a small vessel capable of insertion into a glovebox through a gloveport. This system will initially be used to determine basic information regarding losses of volatile melt constituents in various process conditions, and to evaluate advanced crucible and mold materials to eliminate the use of wash coatings and quartz molds. The quality and reliability of fuel slug casting in various casting approaches and pressure differential strategies will then be evaluated. As process development progresses, the small scale tests will be used to validate casting modeling for mold design of the engineering-scale and larger processes. When the casting process has been optimized, the bench-scale caster will be transferred into one of several transuranic-capable gloveboxes at INL and used to cast minor actinide-bearing fuel slugs.

While tests have begun in the 50-300 gram range in the bench-scale caster, the engineering-scale system will be constructed and installed in a large inert-atmosphere glovebox. This system will is designed to process $6 \mathrm{~kg}$ of material into approximately 60 fuel slugs, and will initially be set up for operation in the configuration favorably demonstrated in the bench-scale caster. The system will have the capability for configuration for a variety of casting techniques, including cold crucible technology. The $6 \mathrm{~kg}$ and 60 -slug scale provide a sufficient scale for applicability to the approximately $25 \mathrm{~kg}$ batch size limit ${ }^{1}$ of a commercial process.

Based on the experience with the ECS, a similar design (the ACS) will be developed and remotized for installation into RSFFF in the Fuel Conditioning Facility (FCF).

Design concepts have been developed and reviewed for both test bed systems to be built in support of ACS design.

\footnotetext{
${ }^{1}$ Limited by criticality concerns
} 


\subsection{Objectives of ACS Test Bed Systems}

\subsubsection{Bench-Scale Casting System}

The bench-scale casting system (BCS) is a small, mobile, and flexible test setup. This system will scope melt constituent volatility issues, crucible and mold materials, and evaluate several casting processes. The system will then be transferred to an actinide-capable glovebox, and utilized to demonstrate actinide fuel casting with $99.9 \%$ recoverability of actinides within the system.

The objectives of the bench-scale casting system include:

- Evaluation of losses of volatile melt constituents in various casting techniques.

- Down selection of reusable crucible and mold materials.

- Evaluation of the counter-gravity and bottom-pour casting techniques with differential pressure injection to determine the most successful casting process.

- Collection of casting data for benchmarking of casting modeling for application to larger systems.

- Fabrication demonstration of transuranic-bearing metallic fuel specimens with $99.9 \%$ recoverability of actinides.

\subsubsection{Engineering-Scale Casting System}

The engineering-scale casting system (ECS) will be utilized to demonstrate remotely-operable casting methods at $6 \mathrm{~kg}$ and 60 -slug scale. This provides a sufficient scale for applicability to larger systems, yet keeps process development tests relatively small, and has a design directly relevant to hot cell installation for actinide-bearing fuel casting. The daily throughput of the AFCF in the GNEP program is approximately $10 \mathrm{~kg}$, and due to criticality concerns, the maximum batch size of the metal fuel currently evaluated in GNEP is $25-30 \mathrm{~kg}$. For these scales, $6 \mathrm{~kg}$ and 60 -slugs is a reliable demonstration of feasibility. The engineering-scale casting system will be capable of configuration for both traditional counter-gravity and bottom pour casting methods. It could also be configured for future inclusion of a cold crucible melt containment system or certain configurations of continuous casting. The objectives of the engineering-scale system include:

- Scale-up demonstration of advanced casting process applicable to remote transuranic-bearing metal fuel fabrication for GNEP, AFCF, and RSFFF.

- Scale-up demonstration of casting with minimization of losses of volatile melt constituents.

- Scale-up demonstration of crucible and mold materials identified in bench-scale tests, including determination of lifetime, lifetime costs, and fuel holdup.

\subsection{Timeline}

Deployment of the Advanced Casting System in a hot cell facility can be accomplished in 24-30 months after start of funding in support of advancing AFCRD objectives for qualification of fuel 
and GNEP objectives of demonstrating process equipment for deployment in the Advanced Fuel Cycle Facility.

Assuming that additional funding is available early in FY08, the first phase of the BCS activities (resolution of melt constituent volatility issues, crucible and mold materials, and evaluation of several casting processes) will be completed by end of the third quarter of FY08. Equipment design, qualification, and installation of the ECS in Fuels and Applied Science Building (FASB) will be completed by the end of FY08. The BCS will be transferred to the Casting Laboratory section of the Analytical Laboratory and be operational and fabricating fuel by Dec 2008. Irradiation specimens suitable for irradiation testing will be fabricated by mid FY09.

Given the same assumptions about funding, installation of the ACS in the FCF hot cell can be accomplished at the end of FY09, with fabrication of prototypic fuel specimens fabricated from recycled fuel for irradiation testing in ATR and JOYO in December 2009.

An integrated timeline and schedule for ACS and RSFFF is presented in the RSFFF report (footnote 1).

The demonstration will be considered successful when fuel specimens containing plutonium and minor actinides suitable for irradiation testing in ATR have been remotely fabricated, and TRU loss in a remote environment has been minimized and quantified.

\subsection{Approach to Advanced Casting System Technology}

\subsection{Melting Technology}

Induction heating has been selected as the melting technology for the ACS. Induction heating has been repeatedly demonstrated in long term remote applications, and considerable experience exists at the INL. Induction heating systems are widely scalable and easily automated. The incell portion - the induction coil - is fabricated of solid copper bar and is highly reliable. Induction heating systems can be designed to provide intense metal stirring, and are adaptable to a wide variety of casting techniques and crucible materials. They also can be easily designed to provide extremely rapid heating rates, an advantage when seeking to limit high temperature reactions or losses of volatile constituents.

\subsection{Crucible Technology}

A dual path approach will be applied to optimization of crucible materials for the ACS. Both conventional crucible materials and cold crucible technology will be considered.

\subsubsection{Cold Crucible Technology}

Cold crucible melting technology has been successfully implemented at INL in the laboratory scale casting of TRU fuels for irradiation testing in the Advanced Test Reactor (ATR). The 
melting technology used, non-consumable electrode arc melting, is not amenable to scale up and remote application, however. Earlier development of a liquid metal cooled cold crucible induction melting system at INL showed the applicability of this technology to application in a hot cell environment. The use of a liquid metal coolant negates any operational issues due to introduction of water in a hot cell environment, including criticality and metal-water explosion hazards. The prototype melter was cooled with $\mathrm{NaK}$ (sodium potassium eutectic alloy). Future designs will use an alternate liquid metal coolant that is more amenable to bench top experimentation.

\subsubsection{Conventional Crucible Materials}

Most historic crucible materials used for melt processing of actinides are either limited-life ceramics or materials such as graphite or refractory metal which are wash-coated with a ceramic. Yttria wash-coated graphite has been used extensively at the INL. Unfortunately, wash-coatings are laborious to apply and remove after use, and they create a dross stream with corresponding fuel loss. They must be removed for reapplication of a pristine coating to achieve reliable protection of the crucible. In this development activity, it is desired to identify a crucible system with chemical-resistance to the fuel alloys - especially those containing zirconium - at the $1300^{\circ} \mathrm{C}-1600^{\circ} \mathrm{C}$ casting temperature. It can be expected that most materials will eventually be wetted as they are reused. The material must be sufficiently robust for repeated handling and must not serve as "sink" for the highly reactive minor actinides - as will likely occur with a thick, porous ceramic crucible.

Initial materials which will be evaluated are graphite (a protective carbide layer is formed in some zirconium systems), bare refractory metals, nitride-coated refractory metals, and carbidecoated refractory metals. If bottom-casting techniques are employed, it is possible that wetted crucible systems, such as bare and carbide-coated refractory metals could be successful. One additional consideration is the ability to recover actinides from spent refractory metal crucibles in an electrorefining system, resulting in a low net loss of material.

\subsubsection{Fuel Molds}

Most issues discussed in the previous crucible section also apply to casting molds. The molds must be non-wetting, but do not require long exposure times in contact with molten metal. Materials must be sufficiently inexpensive to fabricate into complicated assemblies. It is possible that the casting process will not be as fast as currently employed with quartz molds. If this is so, the extreme aspect ratio (approximately 15 inches in length and to 0.17 inches in diameter) of the slugs may require mold preheat, and this may preclude the use of common casting materials such as copper or cast iron. Initial materials which will be evaluated include graphite, nitride-coated refractory metal, and zirconium sheaths. 


\subsection{Developmental Casting Systems}

Optimization of casting technology is the major objective of this development effort. Two casting test bed systems are designed to provide flexibility in physical configuration and process control, allowing testing of multiple casting schemes.

\subsection{Bench-Scale Casting System}

The bench casting system (BCS) is a small, mobile melting system for the evaluation of casting methods, materials, and processes at a scale of 50-300 grams and 1 to 3 cast slugs. The benchscale system will be deployed and well into process and materials testing prior to deployment of the engineering-scale system. Testing of both top and bottom casting methods will occur. Numerous materials will be tested for use as either crucibles or molds. The crucibles will have an outer diameter of 1.25 inches and a height of approximately 2 inches. The wall thicknesses will range between 0.060 inches and 0.187 inches. Initial molds will have a length of 10 inches, and a diameter near $4.3 \mathrm{~mm}$.

This system will utilize two electrical outlets and will have self-contained vacuum and cooling systems. The containment vessel will be capable of insertion into a glovebox through an 8 " gloveport, and will either use existing or temporary I\&C and power feedthroughs.

The BCS has multiple functions. Initially it will be operated in the southwest hood of the Fuels and Applied Sciences Building (FASB) for process and materials development. Here testing will be conducted with appropriate alloys of depleted uranium, zirconium, rare earths, and manganese. Manganese is utilized as an americium surrogate due to similarly high vapor pressures. Rare earths are utilized due to their presence in some fuels as residual fission products, and in some cases as plutonium surrogates for crucible and mold materials compatibility.

Following these activities, the system will be transferred into a transuranic-capable glovebox for the casting of transuranic-bearing fuel slugs. It is likely these castings will be conducted in the casting glovebox of the Materials and Fuels Complex Analytical Laboratory. In this case, the castings will be at the 50-100 gram and single-slug scale due to the 3 to 4 gram americium window in the Analytical Laboratory inventory limit. The charge size may be larger if testing is conducted in the Advanced Fuels Casting Initiative (AFCI) glovebox in the Fuels Manufacturing Facility (FMF).

The testing will include:

- Investigation of crucible and mold materials with potential fuel alloys at various process conditions.

- Investigation of the effects of casting process parameters upon loss of manganese and americium.

- Investigation of traditional and novel casting methods at 1-3 pin scale.

- Casting of benchmark cases to assist in casting modeling of larger-scale mold systems. 
A preliminary concept of the bench-scale caster, setup for bottom casting tests, is provided in Figure 1. A preliminary process diagram is provided in Figure 2. Further information about the system is provided in the following sections.

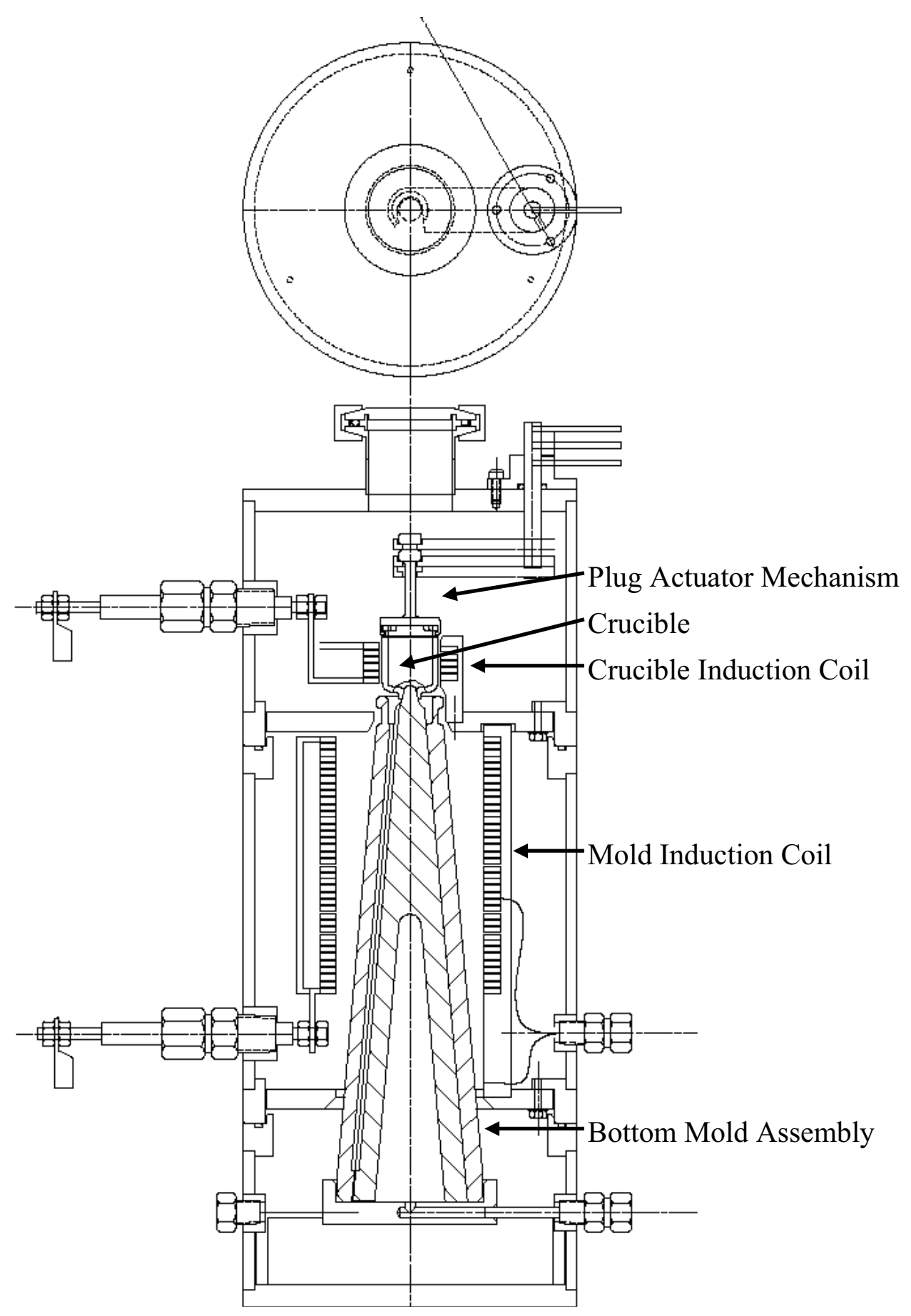

Figure 1 Preliminary Layout of Remote Actinide Casting System configured for Bottom Casting 


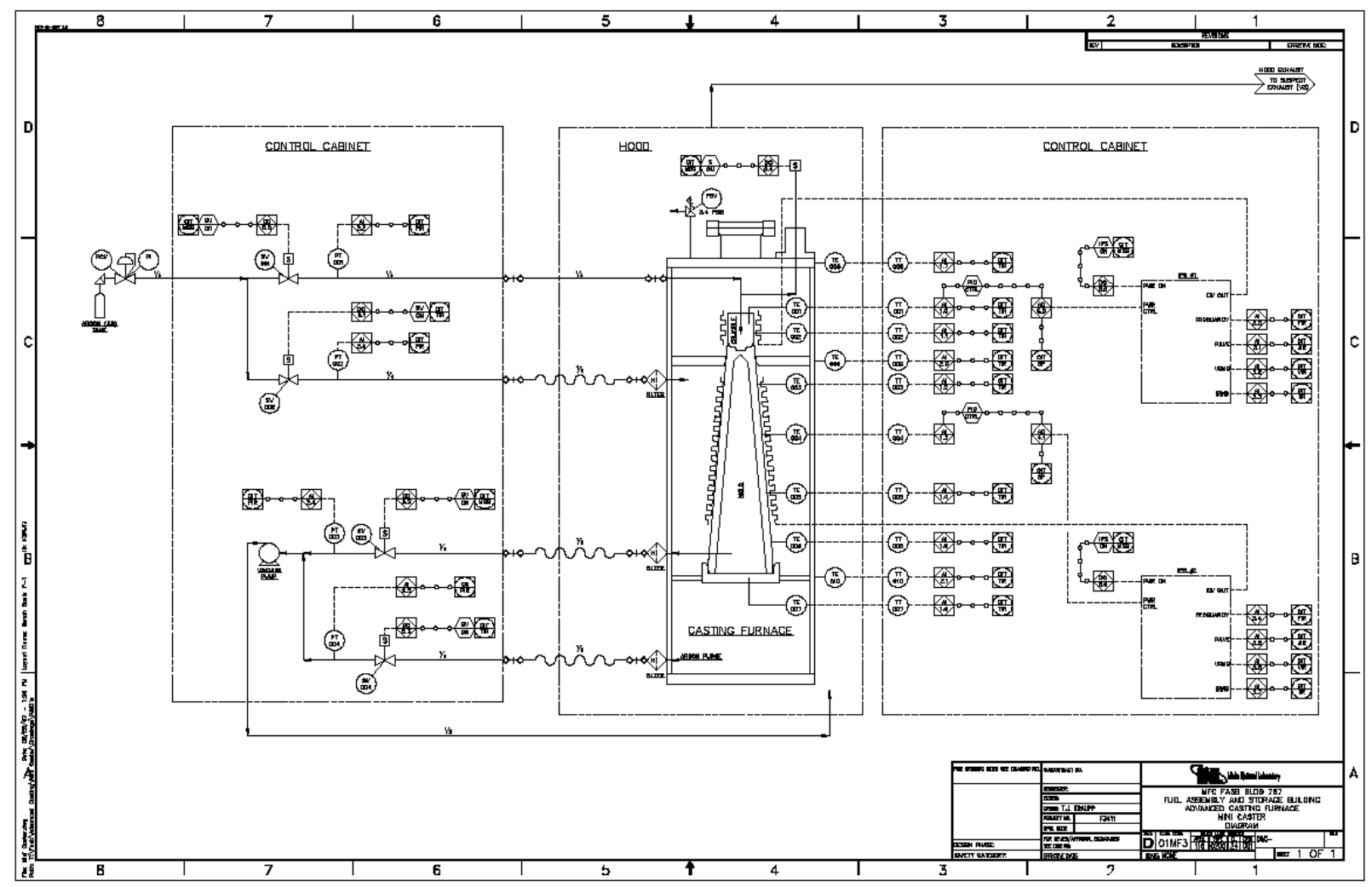

Figure 2 Preliminary Process Diagram for Remote Actinide Casting System

\subsubsection{Design Criteria for the Bench-Scale Casting System}

- operating temperature of $1500^{\circ} \mathrm{C}$,

- crucible outer diameter of 1.25 inches,

- ability to utilize refractory metal or graphite crucibles,

- charge size of 50-300 grams,

- cast slug length of 10 inches,

- flexibility for top or bottom casting,

- scaleable heating technology,

- ability to heat to casting temperature in 10 minutes or less,

- an automated control system, allowing exact repeat of developed casting processes,

- passive containment of molten contents in accident scenarios.

\subsubsection{Control System}

The system will have a small, mobile control and data acquisition system to make tests consistent and reliable. 


\subsubsection{Atmosphere System}

The system will utilize a small dry (oil-less) vacuum pump which operates on standard 110V power. Half-inch vacuum lines, quarter-inch pressure lines and 24-volt solenoid valves will be used. The vessel will be capable of pressurization to $10 \mathrm{psig}$, and will be protected by relief valves.

\subsubsection{Power Supply}

The system will utilize a small commercial induction power supply of $5 \mathrm{~kW}$ powered by 3-phase $208 \mathrm{~V}$. The power supply will be capable of manual or programmed control. The small weldertype closed-loop cooling system is powered by $110 \mathrm{~V}$.

\subsubsection{Coil and Vessel}

The system will be constructed to fit through a standard 8" gloveport. Connections through the vessel will be on the lower plate to allow insertion of an assembled system into a glovebox through a gloveport. The coil and vessel will be uncooled, relying upon thermal mass to maintain low temperatures. Control system interlocks will preclude operation if temperature limits are reached.

\subsection{Engineering Scale Casting System (ECS)}

The ECS will be a test bed capable of configuration for both traditional counter-gravity and gravity-assisted (bottom pour) casting methods. While the INL is most familiar with countergravity injection casting, gravity-assisted casting is the much more common casting method. In this method, the molten alloy is drained into a lower mold system. Actively evacuated molds or pressurized crucible header volume could be used to shorten casting time. This method provides a process advantage in that the casting heel - typically $1 / 3$ of the charge in counter-gravity casting - is completely eliminated. However, this method does provide additional technology unknowns versus INL's traditional method.

The Technical \& Functional Requirements (T\&FR) Document for the ECS has been completed and released as document TFR-434 in INL document control (referred to as the ACS in this document).

\subsubsection{Design Criteria for the Engineering-scale Casting System}

INL T\&FR 434 documents the design criteria for the ECS.

In summary, the criteria are:

- operating temperature of $1500^{\circ} \mathrm{C}$,

- crucible outer diameter of 5.0 inches,

- ability to utilize refractory metal or graphite crucibles, 
- charge size of 6000 grams,

- cast slug length of 15 inches,

- initial cast slug diameter of 0.169 inches

- ability to cast 60 slugs,

- flexibility for top or bottom casting,

- scaleable heating technology,

- remote operable design approach,

- ability to heat to casting temperature in 10 minutes or less,

- an automated control system, allowing exact repeat of developed casting processes,

- passive containment of molten contents in accident scenarios.

\subsubsection{Vessel Design}

The vessel design and layout of the ECS in the FASB glovebox are proceeding. Figures 3 is a plan view of the advanced casting development system in the FASB East Development Glovebox, adjacent to the prototype metal waste form furnace vessel, and Figure 4 is the elevation view. The ECS will be placed to the east of the large prototype metal waste furnace, and west of the $150 \mathrm{~kg}$ balance. Operator access for loading and unloading will be through the north side. Heavier components will be lifted with the glovebox crane, which has travel indicated by the heavy dashed line in the plan view. Sections of the atmosphere control vessel may be placed on the table south of the furnace. Crucibles and molds will likely be prepared in the extension portion of this glovebox, which extends to the right of Figure 3 (east) and setup for ergonomic glovebox activities.

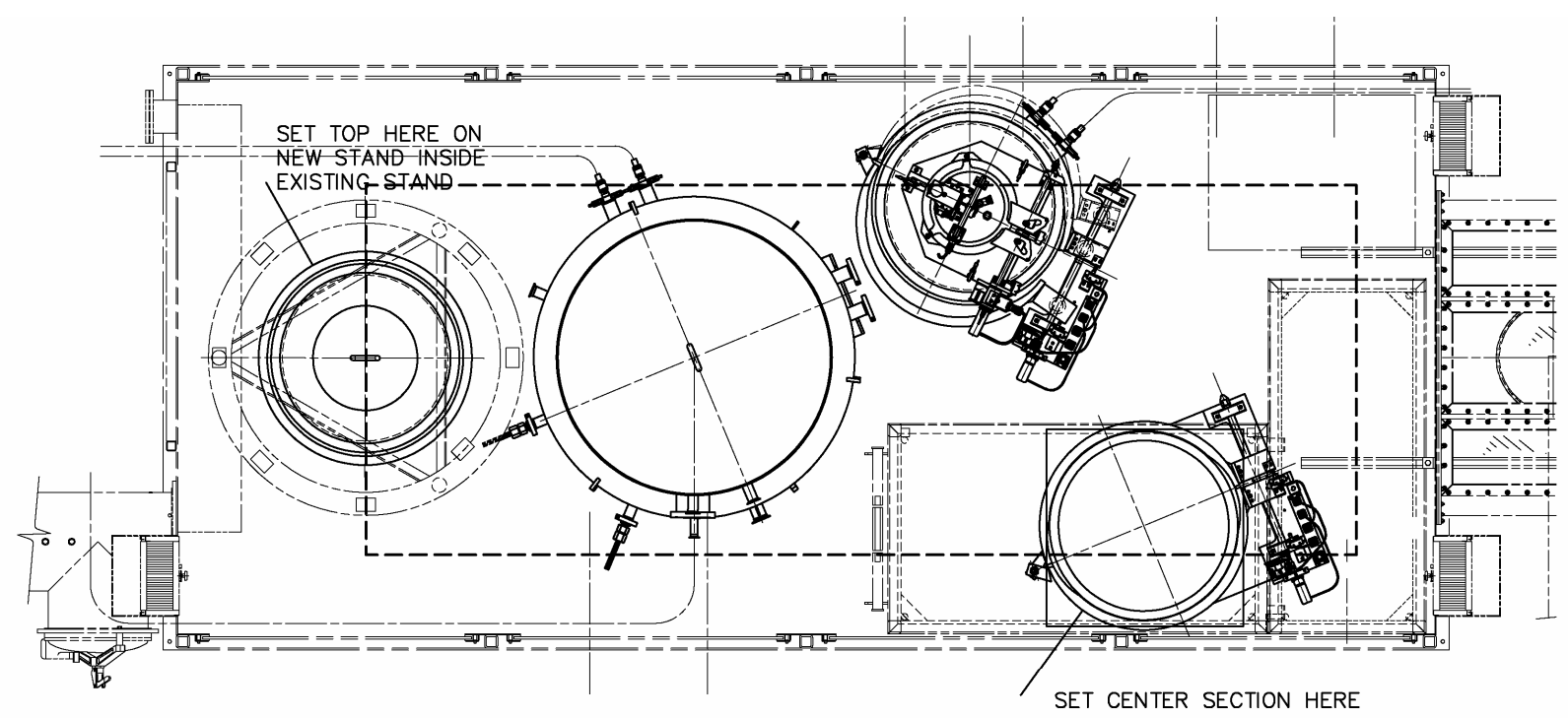

Figure 3 Plan view of the equipment layout for the ECS in the FASB East Development Glovebox 


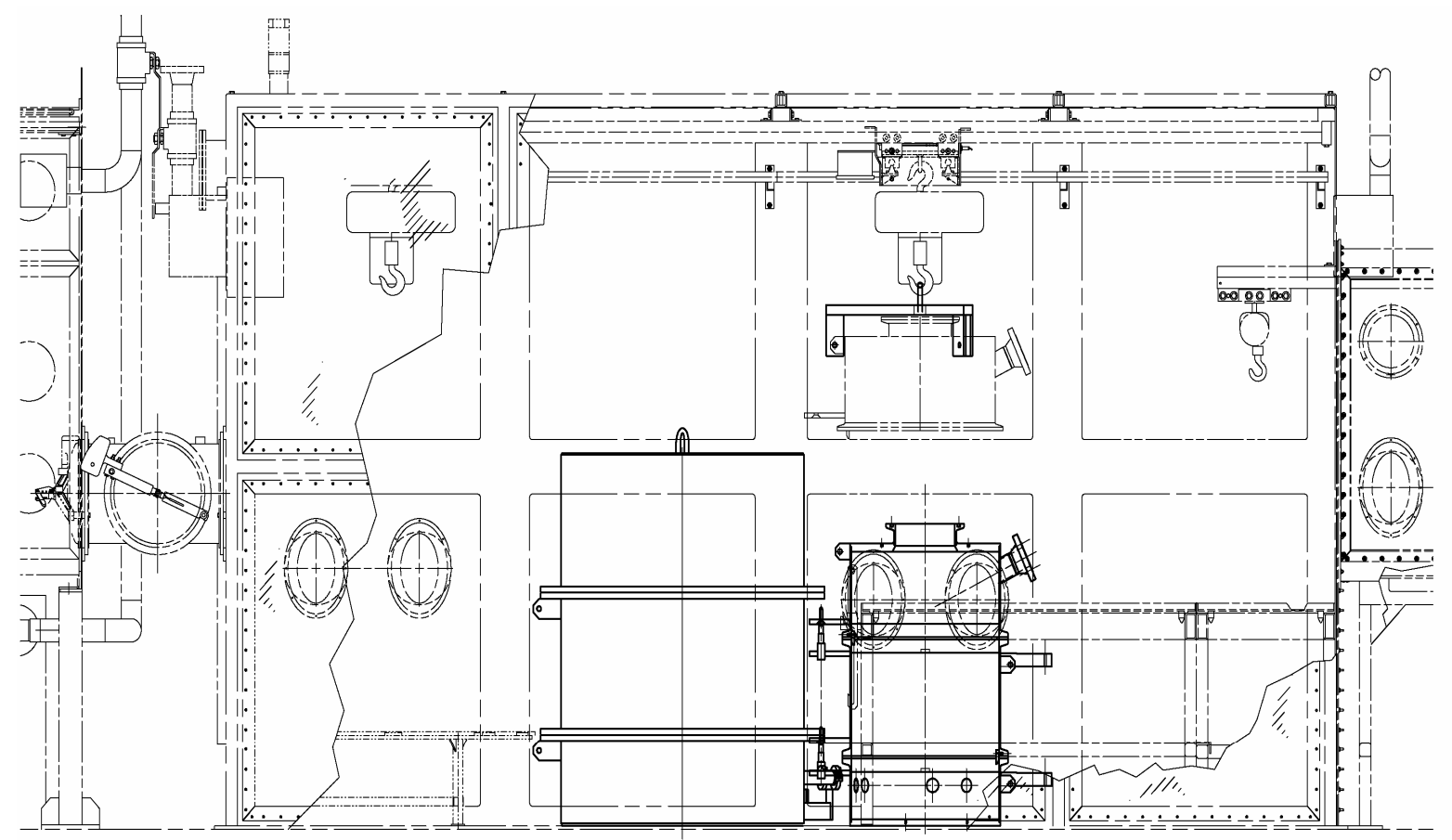

Figure 4 Elevation View of the ECS Preliminary Vessel in the FASB Glovebox

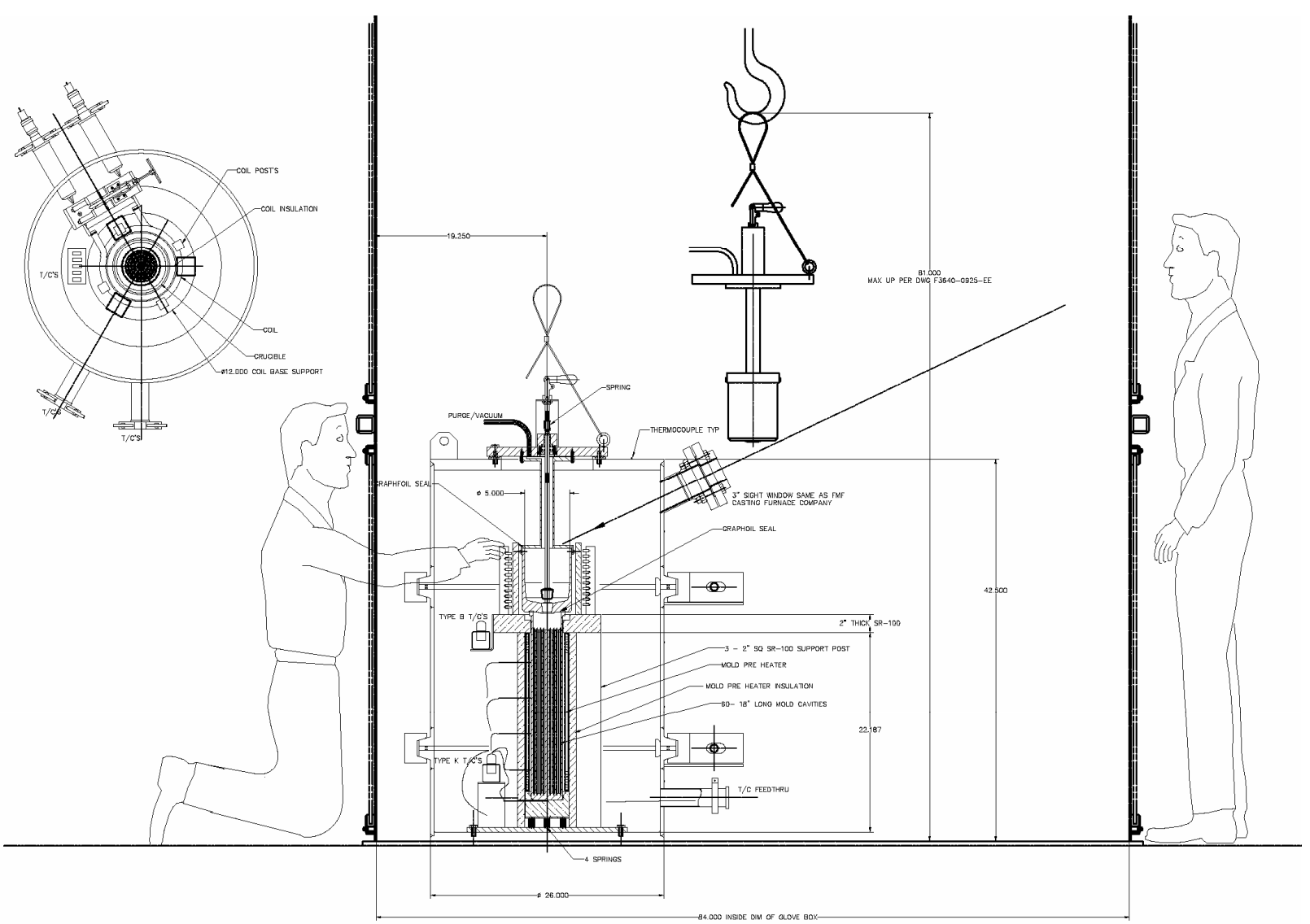

Figure 5 Preliminary Design Concept for Bottom Casting Method in the ECS 


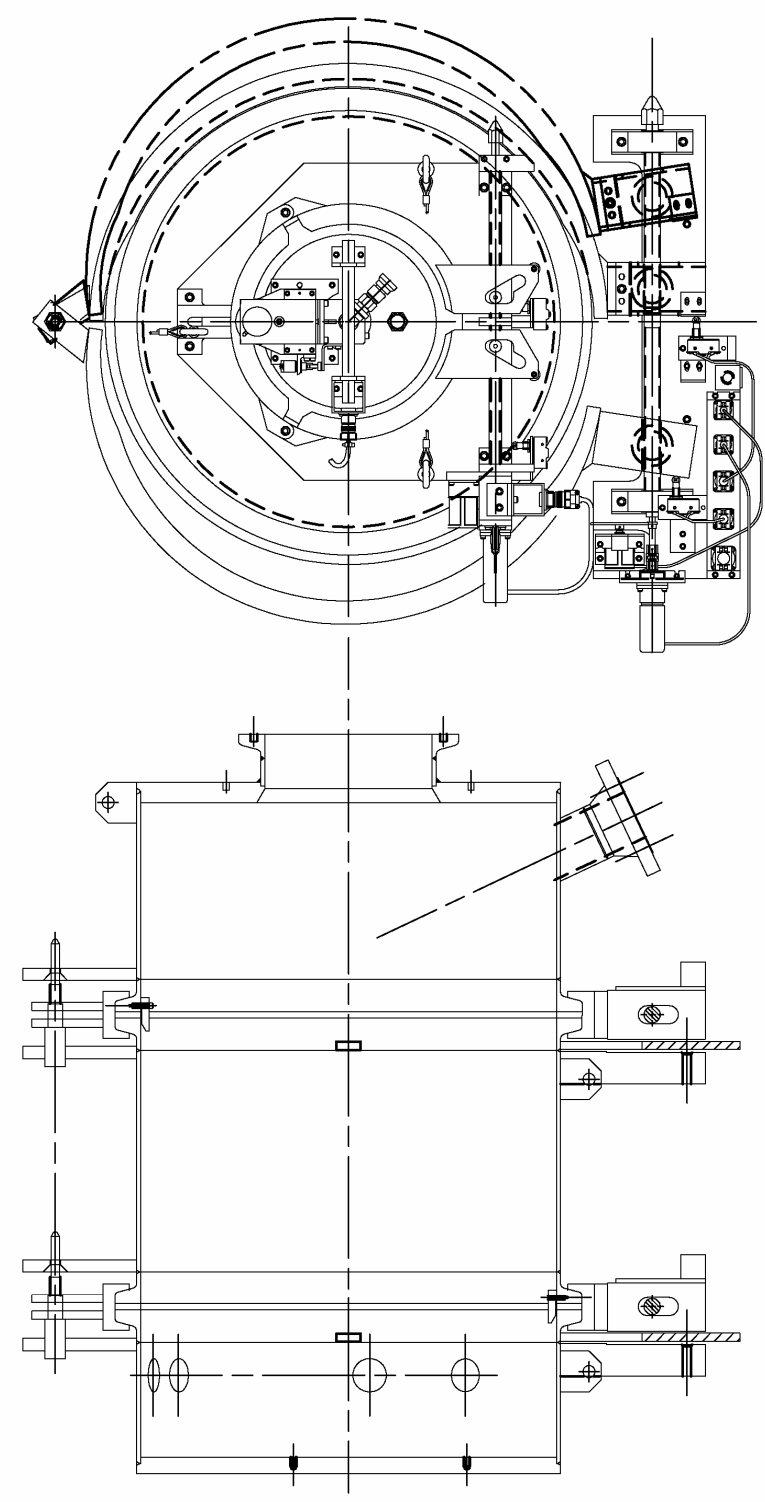

Figure 6 Three section atmosphere vessel for ECS

\subsubsection{Control System Design}

A single mobile control system will be constructed to provide control and data collection of equipment for all tested casting processes. The control panel will be portable and use amphenolstyle interface connections to the glovebox and from the glovebox to the furnace. The control system will be powered by standard $110 \mathrm{~V}$ power. The portable control panel system will contain the following equipment identified for operation:

- Optical Isolators for all input channels to cover at least 32 known inputs

- Control relays for interfacing to 5 DC motors

- Allen-Bradley Control Logix processor 
- Thermocouple input modules sized for of a minimum of 32 inputs (2 modules) - at least 20 type $\mathrm{K}$ and 5 type $\mathrm{B}$

- Analog input module for pressure sensors and possible position sensors/other monitoring capabilities - minimum of 8 inputs

- Relay module for energizing solenoid valves - minimum of 16 relay outputs - operation of 3 vacuum valves and 2 argon valves and 5 DC motors

- Discrete input module for monitoring limit switches (most modules include approximately 16 inputs per module)

- Module to allow communications with the Pachydyne power supply

- Current shunts

- Interposing relays

- E-Stop button to shutdown the heater(s) and the valves deemed necessary

- $24 \mathrm{Vdc}$ power supply for operation of $5 \mathrm{DC}$ brushless motors

- Rack mount computer and 1U 17" LCD drawer with keyboard and touchpad

- RSView32 150 point Human Machine Interface package used for monitoring /control/logging/graphing.

\section{Summary Budget for ACS Test Bed Development}

A summary budget for ACS test bed development is presented below. Costs for operation and remotizing of the ECS for subsequent installation as ACS in RSFFF will be developed next fiscal year (FY08) assuming funding.

Table 1 Preliminary year one budget for ACS tasks

\begin{tabular}{|l|l|l|l|}
\hline Task & Hours & Materials (K) & Cost (K) \\
\hline BCS & 2300 & 80 & 407 \\
\hline ECS in FASB Glovebox & 6552 & 170 & 1100 \\
\hline Total & $\mathbf{8 8 5 2}$ & 250 & 1507 \\
\hline
\end{tabular}

\section{Summary}

Issues critical to fabrication of transuranic-bearing fuels include losses of volatile constituents from the crucible during heating and casting, fuel holdup in crucibles and molds, fuel lost into dross from crucible and mold wash coatings, and the generation of contaminated wastes such as quartz mold pieces.

Implementation of the RSFFF and Advanced Casting Furnace (ACS) builds upon previous fully remote fuel fabrication work completed as part of the EBR-II fuel cycle demonstration that began in the 1960's [2] and the Integral Fast Reactor Program in the 1980's and 1990's. During the earlier campaign, more than 30,000 fuel pins were remotely fabricated in the FCF (Fuel Conditioning Facility), the proposed location for RSFFF. Small scale research conducted as part 
of the Advanced Fuel Cycle Initiative (AFCI) Fuel Development Program has shown that americium loss issues associated with the fabrication of the americium-bearing X501 experiment in the early 1990's [3] are understood and can be overcome using relatively simple engineering measures.

GNEP TRU fuel fabrication requirements will be met through the development of an Advanced Casting System (ACS) that is designed to meet GNEP program requirements for TRU loss and its installation into RSFFF. The ACS effort was initiated as a process and technology development effort to demonstrate minimal actinide fuel loss by rapid melting and casting under careful atmosphere control in reusable crucibles and molds. Development of the ACS includes:

- Design and construction of a bench-scale casting system for use with minor actinide bearing fuel alloys to demonstrate minimal TRU loss

- Design and construction of an engineering-scale metal fuel casting system to demonstrate scale up

- Installation of a remotized ECS into RSFFF to constitute an advanced remotely-operable casting process which meets GNEP objectives. This system is called the ACS.

\section{References}

1. PLN-2428, "Implementation of a Remote Research scale Fuel fabrication Facility (RSFFF) for fabrication of Minor actinide Bearing Fuels at the Idaho National Laboratory (INL)", rev 0, March 29, 2007

2. Charles E. Stevenson, The EBR-II Fuel Cycle Story, American Nuclear Society, 1987.

3. C. L. Trybus, J. E. Sanecki, and S. P. Henslee, "casting of metallic fuel containing minor actinide additions”, Journal of Nuclear Materials 204, pp. 50-55 (1993). 